\title{
Internet of Things (IoT) for Smart Farming: A Systematic Review
}

\author{
Safianu Omar \\ Department of Information Technology \\ Islamic University College, Ghana
}

\begin{abstract}
The world population growth is projected to increase in the coming years and it brings along challenges such as food insecurity and increasing demand for food as a result of production challenges. For these reasons, sustainable and innovative agriculture practices are given higher priority. Smart farming is one of the innovative practices which has seen a significant growth as a result of improved technology and it is a novel farm management method that uses technologies to optimize farming activities and increase productivity. Many reviews on application of IoTs for farming have been published which shows significant contributions in this area of research. In existing reviews, the focus is mainly on areas like Unmanned Aerial Vehicles (UAC) and network topologies, technologies and protocols. This work uses the Preferred Reporting Items for Systematic Reviews and MetaAnalyses (PRISMA) methodology to make a systematic review of current state of IoTs for farming by identifying the state-of-the-art sensing, networking, communication and data management technologies commonly used to implement the solution. The work demonstrates the growing importance of IoTs in farm management and reveals a significant improvement in the way sensor data are stored and processed. It also shows a rise in the usage of supporting technologies like cloud computing, artificial intelligence and image processing techniques for storing and processing big data in efficient and less tedious ways.
\end{abstract}

\section{General Terms}

IoT Application, Smart Farming, Smart Agriculture, Farm Monitoring, Wireless Sensor Network, Internet of Things

\section{Keywords}

IoT Ecosystem, IoT Platform, IoT Topology, Sensor Devices, Big Data, Data Processing Technologies.

\section{INTRODUCTION}

In recent years, food security has seen a significant focus in the global community as the world population growth increases and it is projected to reach 8.7 billion by 2030 [1]. Population growth means an increasing demand for food, yet, production challenges persist resulting in an increasing global hunger. Zero hunger, which is the UN Sustainable Development Goal two (SDG2), aims to attain food security by 2030 through promoting sustainable agricultural practices in the world [2]. As a result, innovative farming and agricultural practices are given higher priority [3,4]. Smart farming is one of the innovative practices which has seen a significant growth as a result of improved technology and it is a novel farm management method that uses technologies to optimize farming activities and increase productivity $[5,6]$. Technologies used in smart farming include the Internet of Things (IoT), Artificial Intelligence (AI), drones and robotics. The main driver of smart farming is IoT- an internetworking of sensors and smart devices embedded in the farm to optimize farming activities. The IoT has offered a new method to record, measure and optimize growth factors on a farm and is changing how farming is practiced.

Recently, many reviews on application of IoTs for farming have been published which shows significant contributions in this area of research. In existing reviews, the focus is mainly on areas like Unmanned Aerial Vehicles (UAC) and network topologies, technologies and protocols. This work complements the existing reviews by making a systematic review of current state of IoTs for farming by identifying the state-of-the-art hardware, network protocols and technologies being used to implement the solution. To do this, only literature published from 2015 to 2020 was considered. This gives the work a new and current perspective about smart farming and adds to the literature by discovering a surge in the usage of modern tools for data processing like machine learning, big data analytics, and cloud computing.

\section{METHODOLOGY}

This work explores works and projects related to the application of IoT technologies for farming with the aim of highlighting the current state in that area. Four steps were used in the literature review process:

1. Formulation of research questions and objectives

2. Search strategy

3. Literature selection process

4. Data (information) gathering from selected works

\subsection{Research Questions and Objectives}

The first step in the research process was to formulate the questions and their corresponding objectives that would guide this work. The research questions are presented below:

RQ1. What areas of farming are IoT systems being used?

RQ2. What sensing, networking, communication and data management technologies are commonly used?

The objectives, which are also motivation for this work are:

1. To find out farming areas where IoT applications are used.

2. To identify the IoT ecosystem in smart farms.

\subsection{Search Strategy}

The search concentrated only on primary studies. Four databases were used in this exercise and they are: JSTORE, IEEE Xplore, ACM Digital Library, and ScienDirect. A set of key terms related to the research questions were listed for the search and they are: smart, farming, IoT, Internet of Things, sensors, devices, technologies, and protocol. Then, a search string was constructed by merging the key terms using the Boolean search operators "AND" and "OR". The structure of the search string is presented in table 1 . 
Table 1: Databases and key terms used for searching

\begin{tabular}{|l|l|}
\hline \multicolumn{1}{|c|}{ Database } & \multicolumn{1}{c|}{ Search String } \\
\hline JSTORE & $\begin{array}{l}\text { ('"Smart" OR "IoT" OR } \\
\text { "Internet of Things" OR } \\
\text { "Sensors" OR "Devices" OR } \\
\text { "Technologies" OR "Protocol") } \\
\text { IEEE Xplore } \\
\text { AND ("Farming" OR } \\
\text { "Agriculture) }\end{array}$ \\
\cline { 1 - 1 } ACM & \\
\hline
\end{tabular}

\subsection{Literature Selection Process}

As explained in section 2.2 the literature search entailed searching for works in the databases using the search string which limited the search results based on the criteria given using the key words. The PRISMA methodology was then used in selecting the review papers. The process is illustrated in figure 1 below:

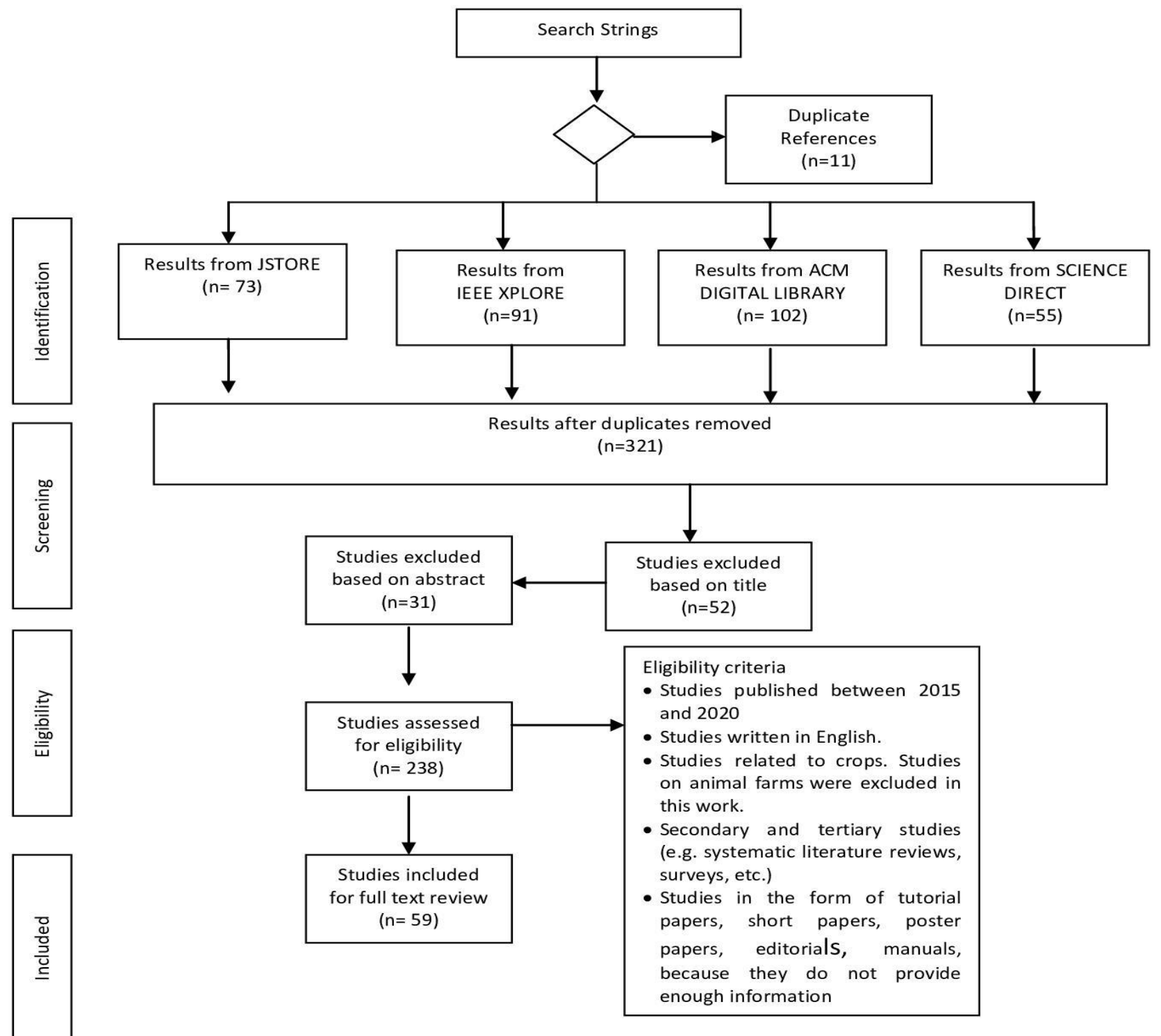

Figure 1: Literature search and selection process using the PRISMA method

The literature selection process entailed four step as follows:

1. Identification: this step involves implementing the search strings in table 1 . The total number of studies gathered in this step was 321 .

2. Screening: In this step, the papers whose titles were not directly related to the application of the internet of things in farming were excluded and papers whose abstract was not categorical on IoT applications in farming were removed. The total number of papers removed in this step was 52 and 31 respectively.

3. Eligibility: The number of studies assessed for eligibility was 238 . The following inclusion and exclusion criteria were used.

- Studies published between 2015 and 2020.

- Studies written in English. 
- Only studies related to crops were considered (Studies on animal farms were excluded in this work because of sensor mobility effects on signal which deserves a specific review.

- Secondary and tertiary studies (e.g. systematic literature reviews, surveys, etc.).

- Studies in the form of tutorial papers, short papers, poster papers, editorials, manuals, because they do not provide enough information

4. Included: After the eligibility assessment, 59 works passed the test and were selected for full text review.

\section{DISCUSSION OF RESULTS}

This section makes an analysis of the selected papers with the aim of realizing the research objectives.

\subsection{IoT Applications}

Generally, in the reviewed papers the following areas have been found to be the common areas where IoT solutions are being implemented:

- Crop Monitoring

- $\quad$ Soil Monitoring

- Irrigation Management

- Disease Control

- Fertilizer and Pesticide Management

Table 3 presents the reviewed papers based on the environment and area of application.

Table 2: Areas of IoT Applications in Smart Farming

\begin{tabular}{|l|c|c|c|}
\hline \multicolumn{1}{|c|}{$\begin{array}{c}\text { Application } \\
\text { Area }\end{array}$} & $\begin{array}{c}\text { Farm Land } \\
\text { (outdoor) }\end{array}$ & $\begin{array}{c}\text { Greenhouse } \\
\text { (indoor) }\end{array}$ & Others \\
\hline $\begin{array}{l}\text { Crop } \\
\text { Monitoring }\end{array}$ & {$[7-19]$} & {$[31-34]$} & {$[38,39]$} \\
\hline Soil Monitoring & {$[20,45,46]$} & - & {$[40]$} \\
\hline $\begin{array}{l}\text { Irrigation } \\
\text { Management }\end{array}$ & {$[21-24]$} & {$[35,36]$} & {$[41]$} \\
\hline $\begin{array}{l}\text { Disease } \\
\text { Monitoring }\end{array}$ & {$[25,26]$} & {$[37]$} & {$[42]$} \\
\hline $\begin{array}{l}\text { Fertilizer and } \\
\text { Pesticide } \\
\text { Management }\end{array}$ & {$[27,28]$} & {$[31]$} & - \\
\hline Others & {$[29,30]$} & {$[38]$} & {$[43,44]$} \\
\hline
\end{tabular}

As shown in Table 3, crop monitoring is the topmost area where IoT solutions are applied for smart farming in both farm fields and greenhouses. This shows the relevance of crop monitoring to farmers. The solutions were developed to gather data such as the conditions of rice and maize crops $[14,13]$ and manage the conditions of greenhouses [31,32]. Next comes IoT applications for soil monitoring. These solutions are able to gather data on the level of moisture in the soil in order to know the pattern or level of water consumption and analyze the soil nutrients $[40,45,46]$. Also, table 3 reveals irrigation management as one of the areas where IoT solutions are being utilized. In this area, the IoT solutions are utilized for effective usage of water by deploying sensors for the measurement of soil moisture and using the acquired data to control the source and flow of the irrigation [22, 23] and in some cases using humidity and weather datasets to regulate the quantity of water needed for irrigation [24, 35, 36]. Disease control and prevention is one of the application areas of IoT for smart farming. In this solution, environmental and plant data like plant image [25], temperature and humidity [37] are processed with image processing technologies [25] and artificial intelligence [37] to identify the type of disease or forecast the occurrence of disease. Other IoT solutions presented in table 3 are developed to manage application of pesticide and fertilizers on crops. Thus, the solutions gather salinity, $\mathrm{pH}$ and nitrogen data from the crops, analyze it and identify spots where pesticides or fertilizer are required $[27,28]$.

Each of the application areas highlighted in Table 3 has its shortcomings. Communication challenges between sensors- as a result of limited distance coverage, poor signal and weather patterns-e.g. rain- have impact on the nodes and the data they gather $[9,38,29]$.

\subsection{IoT Ecosystem for Smart Farm}

The IoT ecosystem in smart farms consists of many devices and softwares that work together to capture signal and forward it for processing. This section presents the IoT components as used in the reviewed papers.

\subsubsection{Sensors}

Sensors are the primary physical objects connected to the IoT system. In the reviewed papers, solutions that used readymade sensors constitute $98 \%$ while $2 \%$ used custom made sensors. The overwhelming usage of ready-made sensors signifies the affordability and meeting the needs for smart farming. As shown in Table 4 such sensors have the capacity of gathering real-time data on weather, chemical compounds like carbon dioxide concentration, soil properties and plant images.

Table 4: Sensors and their area of applications in the reviewed papers

\begin{tabular}{|l|l|}
\hline Application Area & \multicolumn{1}{|c|}{ Sensing Area } \\
\hline \multirow{4}{*}{ Crop Monitoring } & Disease and Insects Sensing [13, 28] \\
\cline { 2 - 2 } Soil Monitoring & Plant and Crop Growth [47, 48] \\
\hline \multirow{5}{*}{ Environment } & Chemical Elements [49] \\
\cline { 2 - 2 } Monitoring & Temperature and Moisture [40, 45, 50] \\
\hline & Temperature and Humidity [51, 23] \\
\cline { 2 - 2 } & Luminosity [49, 22] \\
\cline { 2 - 3 } & Wind direction and Speed [52] \\
\cline { 2 - 3 } & Rain [33] \\
\cline { 2 - 2 } & Carbon dioxide concentration [51] \\
\cline { 2 - 2 } & Atmospheric pressure [52] \\
\hline
\end{tabular}




\subsubsection{Network Protocols, Topologies and \\ Platforms}

When sensors collect data, it is sent to a server or database via a platform. The network configuration for such communication can be wired or wireless. In the reviewed papers, Ethernet was the choice of protocol for wired networks, ZigBee Wifi and Bluetooth were used for short range wireless networks, and LoRaWAN, GPRS and 3G for long range wireless networks. Table 5 presents the network protocols used in the reviewed papers.

Table 5: Network Protocols used in the various smart farm solutions in the reviewed papers

\begin{tabular}{|c|c|c|c|c|c|}
\hline $\begin{array}{c}\text { Network } \\
\text { Type }\end{array}$ & Range & Protocol & $\begin{array}{l}\text { Farm } \\
\text { Land }\end{array}$ & $\begin{array}{l}\text { Green } \\
\text { house }\end{array}$ & Others \\
\hline Wired & Short & Ethernet & - & [53] & [48] \\
\hline \multirow{6}{*}{ Wireless } & \multirow{2}{*}{ Short } & ZigBee & $\begin{array}{c}{[15,21,} \\
29]\end{array}$ & [32] & [27] \\
\hline & & Bluetooth & [54] & [55] & - \\
\hline & \multirow[t]{2}{*}{ Medium } & WiFi & $\begin{array}{l}{[20,22,} \\
25,26,]\end{array}$ & $\begin{array}{c}{[34,} \\
49,51, \\
55]\end{array}$ & [48] \\
\hline & & RF-ISM & [8] & [38] & - \\
\hline & \multirow[b]{2}{*}{ Long } & $\begin{array}{c}\text { LoRaWA } \\
\mathrm{N}\end{array}$ & [17] & [37] & [42] \\
\hline & & $\begin{array}{c}\text { Cellular } \\
\text { (GPRS or } \\
3 G)\end{array}$ & $\begin{array}{c}{[21,22,} \\
23,25 \\
, 30,52,5 \\
4]\end{array}$ & $\begin{array}{c}{[32,33} \\
, 34,49 \\
]\end{array}$ & [45] \\
\hline
\end{tabular}

As presented in Table 5, different network protocols were used in different farming environments to establish data communication either in a short or long range network architecture. It can be observed that WiFi and cellular (GPRS or $3 \mathrm{G})$ networks are the most widely used networks. The wide usage of WiFi can be due to its ubiquitous nature and ease of implementation. Its high energy consumption is, however, a challenge hence low energy consumption protocols such as ZigBee and Bluetooth, are used in other solutions. The extensive usage of cellular networks on the other hand is on account of its long distance coverage technology and transmission of high data rate. LoRaWAN, a low energy consumption protocol, was deployed for long range communication as a substitute in places where cellular network coverage is limited.

Sensor technology is not without challenges. The distance between nodes in IoT solutions can have an impact on signal communication. Again, the plantation itself, as investigated by [29] and [56] who studied its effects on signal communication, can be an impediment for transmission. Other challenges are specifically faced in greenhouses where the proximity of sensors on wireless networks could lead to interference $[55,38]$. This challenge can be rectified by using wired network technologies such as Ethernet [53].

Another key feature of IoT solutions is the network topology. Depending on the architecture, three topologies- star, tree or mesh- are usually used in a sensor network [57]. In twentyseven percent $(27 \%)$ of the reviewed papers it is possible to see clearly the type of network topology used for the IoT solution. For example, in [60] a star topology was adopted on LoRa protocol for connecting sensor nodes to a coordinating node that serves as a gateway to a cloud application for controlling irrigation. Mesh topology is deployed in [55] for monitoring a greenhouse while a tree topology is implemented in [57] for monitoring crops.

The type of topology used may have a significant effect on the distance between nodes and the number of nodes in the network [58]. In star topology for instance the architecture consists of a coordinating node (master) and slave nodes where the slave nodes send data to the coordinating node. The distance between master and slave nodes can be restricted by the physical layer standards of star network topologies. Tree or cluster topology merges several star networks where all sensor nodes have the same communication rights. In such topology, two features are apparent: a sink node and a routing tree. The routing tree connects every single node to the sink. This puts the connectivity of the nodes in a one-hop communication with the sink node, which may result in many traffic and data loss [61]. In mesh topology, each single node is a free routing agent which makes multi-hop communication possible; hence network coverage in mesh topology is better [59]. Though mesh networks are complex they are more dependable because of communication redundancy between sensor nodes, a feature that prevents the failure of data communication [55].

Sensor network topologies are supported by embedded system platforms and are used as gateways in IoT solutions. In the $27 \%$ reviewed papers which is possible to see clearly the type of network topology used, they either used Arduino, Raspberry Pi or ESP. The extensive usage of these platforms may be because they are cost-effective and they allow the implementation of different protocols and act at the same time as transceivers. This unique feature enables such platforms to serve as sub-nodes or coordinating nodes in star networks or as routers in mesh networks $[10,60]$. Thus, Raspberry Pi is the choice of platform for star topology, Arduino is used in all the three topologies and mostly for node and device connections, ESP is frequently utilized for star network topology and point-to-point communication.

The platforms also serve as gateways and are capable of transmitting data to the cloud via the application protocol. Three application protocols, MQTT, CoAP and HTTP, are the choice of protocols implemented in the review papers. The protocols use subscriber/publisher modules which are suitable for devices in the IoT architecture which have limited computing capacity and also ensure compatibility between non-standardized devices and platforms. Among the three application protocols, MQTT is favorable for smart farming solutions for its interoperability across various network protocols, resiliency and better transmission rate [49]

\subsubsection{Data Processing Technologies for Smart}

\section{Farming}

In the past years, the main purpose of IoT applications was to gather and store data from sensors using simple processing solutions. Recently, emerging and powerful technologies such as cloud computing and artificial intelligence are being used extensively as supportive technologies to process and store the big data collected from agriculture activities. As shown in figure 2 , the most widely used supporting technology in the smart farming solutions in the reviewed papers is cloud 
computing used by 51 papers, followed by machine learning used by 17 papers, computer vision used by 7 papers, big data used by 5 papers, and fuzzy logic used by 2 papers.

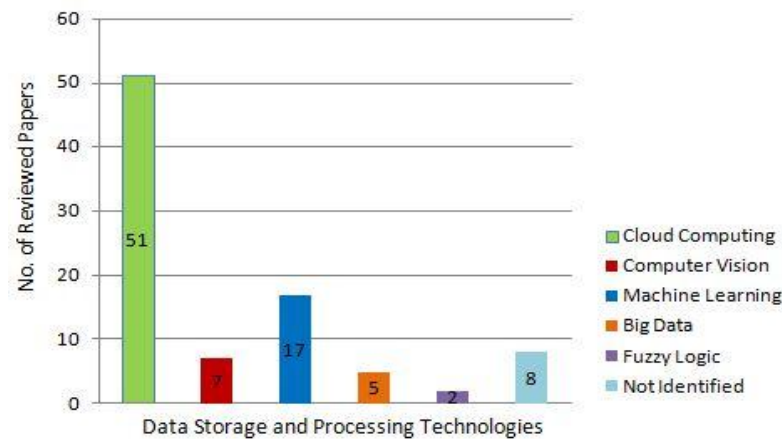

Figure 2: Data processing technologies used in the reviewed papers

IoT infrastructure for smart farming produces big data that is used to generate information about crops and their environment. The unstructured set of data needs technologies to reduce the processing time and storage. Cloud platforms provide data analysis panels that allow the integration of multiple data and real-time monitoring of the collected data. In the reviewed papers, the most widely used cloud-based platform is ThingSpeak. Other cloud-based platforms used are AWS IoT, FIWARE and Thinger.io. The wide usage of ThingSpeak is for the fact that it has a little infrastructure requirements and it is open-source [60]. The cloud-based platforms provide different services, however, all have data storage functionality $[10,53,62]$ and data processing and visualization services [62]. Thus, the cloud-based platforms provide data storage and processing services at the same time. The data processing service includes modules such as machine learning, big data analytics, fuzzy logic, etc. Table 6 shows the technologies used for data processing in the reviewed papers.

Table 6: Data processing technologies and their usage in smart farming

\begin{tabular}{|c|c|c|c|c|}
\hline $\begin{array}{c}\text { Application } \\
\text { Area }\end{array}$ & $\begin{array}{c}\text { Big } \\
\text { Data }\end{array}$ & $\begin{array}{c}\text { Artificial } \\
\text { Intelligen } \\
\text { ce/ } \\
\text { Machine } \\
\text { Learning }\end{array}$ & $\begin{array}{c}\text { Computer } \\
\text { Vision }\end{array}$ & $\begin{array}{c}\text { Fuzzy } \\
\text { Logic }\end{array}$ \\
\hline $\begin{array}{c}\text { Crop } \\
\text { Monitoring }\end{array}$ & {$[10,27]$} & $\begin{array}{c}{[9,10,12,} \\
30,63,67]\end{array}$ & $\begin{array}{c}{[14,15,25,} \\
47]\end{array}$ & {$[63]$} \\
\hline $\begin{array}{c}\text { Soil } \\
\text { Monitoring }\end{array}$ & {$[46]$} & {$[20,46]$} & - & - \\
\hline $\begin{array}{c}\text { Irrigation } \\
\text { Management }\end{array}$ & {$[23,41]$} & {$[23,24,67]$} & - & {$[36]$} \\
\hline $\begin{array}{c}\text { Disease } \\
\text { Monitoring }\end{array}$ & - & {$[27,64$,} & {$[27,65]$} & - \\
\hline $\begin{array}{c}\text { Fertilizer and } \\
\text { Pesticide } \\
\text { Management }\end{array}$ & - & $\begin{array}{c}{[27,} \\
64,65]\end{array}$ & {$[65]$} & - \\
\hline
\end{tabular}

As shown in table 6, artificial intelligence, computer vision and big data are the most frequently used technologies for processing data in smart farm solutions because of their potentiality to process huge data within a short period. Table 6 also reveals that the most applicable area in smart farming for data processing technologies is crop monitoring. Big data was used for soil and crop monitoring and irrigation management. In $[23,46]$ big data technology was used to capture and process data on soil and crops to optimize the quantity of water for irrigation, assisting the farmer to access market information based on the processed data-e.g. to purchase seeds and fertilizers- and generate information on related agriculture activities. Again, in [64] big data technology was implemented in a decision support system with a knowledge based module to advise farmers on irrigation cycles.

Managing sensor data automatically hinges on the analysis and manipulation of various variables. In simple IoT solutions in outdoor farms data on soil temperature or humidity can be used to activate irrigation systems. This process is quite complex in the case of greenhouse farming where a change in one variable can have an effect on others $[51,66]$. As shown in table 6, fuzzy logic was implemented in solutions that require working with more than one parameters like crop monitoring and irrigation. In [66] for instance, fuzzy logic was used to analyze humidity and temperature in a greenhouse to determine the time the irrigation and cooling systems should be activated. Generally, machine learning can also be used to process multiple dependent crop or environmental variables. For instance, in [67] machine learning was used in processing data to forecast the weather based on temperature and humidity and, based on the forecast, to activate the irrigation system. Machine learning was also used to process multiple imagery data like texture and color to find spots on the plants in order to predict or ascertain the emergence of diseases and their growth stages $[14,65]$. Table 6 also shows computer vision was used for data processing in IoT solutions that require imagery data in monitoring crops and diseases. Computer vision enables the spotting of ripe fruits and diseases and pests invasion [14,15, 25] and in [65] computer vision was used to analyze crop data that cause diseases in plants. In [47], computer vision was deployed in robots to detect weeds and eradicate them.

\section{CONCLUSION}

This paper made a systematic review of the usage of IoT in smart farming and presented its ecosystem, network topologies and protocols, and the current data processing technologies being used. Advances in technology makes it possible for the application of IoTs in farms. The scalability provided by sensor technologies, network protocols and platforms, data processing technologies such as big data, artificial intelligence and cloud computing have made it possible to store and process large amounts of data within a short time to improve crop monitoring and make informed decisions. The two main network connections in smart farms are wired and wireless connections. The work reveals that wired connection is used mostly for greenhouse (indoor) farming while wireless connection is used largely for farm fields (outdoor farming). WiFi and cellular (GPRS and 3G) networks are the most widely used networks. The wide usage of WiFi can be due to its ubiquitous nature and ease of implementation. Its high energy consumption is, however, a challenge. The usage of cellular networks on the other hand is on account of its long distance coverage technology and transmission of high data rate. LoRaWAN, a low energy consumption protocol, was deployed for long range communication as a substitute in places where cellular network coverage is limited or in areas with power restrictions. The review also shows that artificial intelligence, 
such as machine learning, is the most frequently used technology for processing data in smart farm solutions because of its potentiality to process huge data within a short period and that the most applicable area in smart farming for data processing technologies is crop monitoring.

The work reveals a significant improvement in the way sensor data are stored and processed. In the past, the main purpose of IoT applications was to gather and store data from sensors using simple processing solutions, making the work tedious and inefficient. The review shows a rise in the usage of supporting technologies like cloud computing, artificial intelligence and image processing techniques for storing and processing big data in efficient and less tedious ways and in a short time. In addition, the reviewed works demonstrated the growing importance of IoTs in farm management. A future work may be expanded to include papers on challenges of IoT solutions and solutions for small scale farms and post-harvest management. Future research directions could also be in the optimization of algorithms for duty cycles in sensor nodes to reduce energy consumption and improve power efficiency in IoT solutions.

\section{REFERENCES}

[1] Committee on World Food Security (FAO). 2012. Coming to terms with terminology: Food Security, nutrition security, food security and nutrition, food and nutrition security, October 15-22, 2012, Rome, Italy.

[2] UNDP. 2016. Sustainable Development Goal 2 (SDG 2): Zero Hunger. Accessed on: April 5, 2020. [online]. Available:

https://www.undp.org/content/undp/en/home/sustainabledevelopment-goals/goal-2-zero-hunger.html

[3] United Nations Children's Fund, World Health Organization, The World Bank, "UNICEF-WHO-World Bank Joint Child Malnutrition Estimates", UNICEF, New York; WHO, Geneva; The World Bank, Washington, DC, 2012.

[4] FAO, IFAD, UNICEF, WFP and WHO., "The State of Food Security and Nutrition in the World 2017. Building resilience for peace and food security", Rome, FAO, 2017.

[5] SciForce, Smart Farming: The Future of Agriculture. Available online: https://www.iotforall.com/smartfarming-future-of-agriculture. (Accessed on 5 September 2020).

[6] Venkatesan, R., Tamilvanan, A., "A sustainable agricultural system using IoT", In: International Conference on Communication and Signal Processing (ICCSP), 2017.

[7] Granell, C., Miralles, I., Rodríguez-Pupo, L., GonzálezPérez, A., Casteleyn, S., Busetto, L., Pepe, M., Boschetti, M., Huerta, J., "Conceptual Architecture and ServiceOriented Implementation of a Regional Geoportal for Rice Monitoring”, ISPRS Int. J. Geo Inf. 2017, 6, 191, doi:10.3390/ijgi6070191.

[8] Uddin, M.A., Mansour, A., Jeune, D.L., Ayaz, M., Aggoune, E., "UAV-Assisted Dynamic Clustering of Wireless Sensor Networks for Crop Health Monitoring", Sensors, 2018. doi:10.3390/s18020555.

[9] Liu, N.; Cao, W.; Zhu, Y.; Zhang, J.; Pang, F.; Ni, J. "Node Deployment with k-Connectivity in Sensor Networks for Crop Information Full Coverage
Monitoring”, Sensors, 2016. doi:10.3390/s16122096.

[10] Alonso, R.S., Sittón-Candanedo, I., García, Ó., Prieto, J., Rodríguez-González, S. "An intelligent Edge-IoT platform for monitoring livestock and crops in a dairy farming scenario", Ad Hoc Network, 2020. doi:10.1016/j.adhoc.2019.102047.

[11] Trilles, S., González-Pérez, A., Huerta, J. “A Comprehensive IoT Node Proposal Using Open Hardware. A Smart Farming Use Case to Monitor Vineyards", Electronics, 2018, doi:10.3390/electronics7120419.

[12] Li, S.; Yuan, F.; Ata-UI-Karim, S.T.; Zheng, H.; Cheng, T.; Liu, X.; Tian, Y.; Zhu, Y.; Cao, W.; Cao, Q. "Combining Color Indices and Textures of UAV-Based Digital Imagery for Rice LAI Estimation", Remote Sens, 2019, 11, 1763, doi:10.3390/rs11151763.

[13] Han, L.; Yang, G.; Yang, H.; Xu, B.; Li, Z.; Yang, X., "Clustering Field-Based Maize Phenotyping of PlantHeight Growth and Canopy Spectral Dynamics Using a UAV Remote-Sensing Approach", Front. Plant Sci., 2018, 9, 1-18, doi:10.3389/fpls.2018.01638.

[14] Li, S.; Ding, X.; Kuang, Q.; Ata-UI-Karim, S.T.; Cheng, T.; Liu, X.; Tian, Y.; Zhu, Y.; Cao, W.; Cao, Q., "Potential of UAV-Based Active Sensing for Monitoring Rice Leaf Nitrogen Status", Front. Plant Sci., 2018, 9, 114, doi:10.3389/fpls.2018.01834.

[15] Mateo-Aroca, A., García-Mateos, G., Ruiz-Canales, A., Molina-García-Pardo, J.M., Molina-Martínez, J.M., "Remote Image Capture System to Improve Aerial Supervision for Precision Irrigation in Agriculture", Water 2019, 11, 255, doi:10.3390/w11020255.

[16] Thakur, D., Kumar, Y., Vijendra, S., "Smart Irrigation and Intrusions Detection in Agricultural Fields Using I.o.T" Procedia Comput. Sci., 2020, 167, 154-162, doi: 10.1016/j.procs.2020.03.193.

[17] Taskin, D., Yazar, S., "A Long-range context-aware platform design for rural monitoring with IoT In precision agriculture", Int. J. Comput. Commun. Control, 2020, 15, 1-11, doi:10.15837/IJCCC.2020.2.3821.

[18] Chen, Y., Chanet, J.-P., Hou, K.-M.; Shi, H., de Sousa, G., "A Scalable Context-Aware Objective Function (SCAOF) of Routing Protocol for Agricultural LowPower and Lossy Networks (RPAL)", Sensors 2015, 15, 19507-19540, doi:10.3390/s150819507.

[19] Xing, H., Xu, X., Li, Z., Chen, Y., Feng, H., Yang, G., Chen, Z., "Global sensitivity analysis of the Aqua Crop model for winter wheat under different water treatments based on the extended Fourier amplitude sensitivity test", J. Integr. Agric., 2017, 16, 2444-2458, doi:10.1016/S2095-3119(16)61626-X.

[20] Vincent, D.R., Deepa, N.; Elavarasan, D.; Srinivasan, K.; Chauhdary, S.H.; Iwendi, C., "Sensors Driven AI-Based Agriculture Recommendation Model for Assessing Land Suitability", Sensors, 2019, $19, \quad 3667$, doi:10.3390/s19173667.

[21] Karim, F., Karim, F., Frihida, A., "Monitoring system using web of things in precision agriculture", Procedia Comput. Sci., 2017, 110, 402-409, doi:10.1016/j.procs.2017.06.083. 
[22] Mohanraj, I., Ashokumar, K., Naren, J., "Field Monitoring and Automation Using IOT in Agriculture Domain", Procedia Comput. Sci., 2016, 93, 931-939, doi:10.1016/j.procs.2016.07.275.

[23] Revathi, N., Sengottuvelan, P., "Real-Time Irrigation Scheduling Through IoT in Paddy Fields", Int. J. Innovative Technology and Exploring. Engineering, 2019, 8, 4639-4647, doi:10.35940/ijitee.J1183.0881019.

[24] Campos, N.G.S., Rocha, A.R., Gondim, R., da Silva, T.L.C., Gomes, D.G., "Smart and green: An internet-ofthings framework for smart irrigation", Sensors (Switzerland), 2020, 20, 190, doi:10.3390/s20010190.

[25] Kumar, S., Mishra, S., Khanna, P., "Precision Sugarcane Monitoring Using SVM Classifier", Procedia Comput. Sci., 2017, 122, 881-887, doi:10.1016/j.procs.2017.11.450.

[26] Pérez-Expósito, J., Fernández-Caramés, T., FragaLamas, P., Castedo, L., "VineSens: An Eco-Smart Decision-Support Viticulture System", Sensors2017, 17, 465, doi:10.3390/s17030465.

[27] Zhai, Z., Martínez Ortega, J.-F., Lucas Martínez, N., Rodríguez-Molina, J., "A Mission Planning Approach for Precision Farming Systems Based on Multi-Objective Optimization", Sensors2018, 18, 1795, doi:10.3390/s18061795.

[28] Cao, Q., Miao, Y., Shen, J., Yuan, F., Cheng, S., Cui, Z., "Evaluating Two Crop Circle Active Canopy Sensors for In-Season Diagnosis of Winter Wheat Nitrogen Status", Agronomy2018, 8, 201, doi:10.3390/agronomy8100201.

[29] Gao, Z., Li, W., Zhu, Y., Tian, Y., Pang, F., Cao, W., Ni, J., "Wireless Channel Propagation Characteristics and Modeling Research in Rice Field Sensor Networks", Sensors, 2018. doi:10.3390/s18093116.

[30] Jin, X.B., Yang, N.X., Wang, X.Y., Bai, Y.T., Su, T.L., Kong, J.L., "Hybrid deep learning predictor for smart agriculture sensing based on empirical mode decomposition and gated recurrent unit group model", Sensors (Switzerland), 2020. doi:10.3390/s20051334.

[31] Zhang, T., Zhou, W., Meng, F., Li, Z., "Efficiency Analysis and Improvement of an Intelligent Transportation System for the Application in Greenhouse", Electronics, 2019. doi:10.3390/electronics8090946.

[32] Junxiang, G., Haiqing, D., "Design of Greenhouse Surveillance System Based on Embedded Web Server Technology", Procedia Eng., 2011, 23, 374-379, doi:10.1016/j.proeng.2011.11.2516. 100.

[33] Hong, L.S., Sa, Z.S., Yan, J., "Environment Factors Monitoring System Based on CAN bus", International Journal of Online and Biomedical Engineering., 2016, 12, 9, doi:10.3991/ijoe.v12i05.5722. 101.

[34] Shasi Kiran, U., Arya, S., Rajasekaran, M., "Design and Implementation of Smart and Low Cost Multi-task Farming System Using Arduino", Int. J. Eng. Technol., 2018, 7, 509, doi:10.14419/ijet.v7i2.24.12148

[35] Abd Rahman, M.K.I., Zainal Abidin, M.S., Buyamin, S., Azimi Mahmud, M.S., "Enhanced Fertigation Control System towards Higher Water Saving Irrigation", Indonesian. Journal of Electrical. Engineering.
Computer. Science, .2018, 10, 859, doi:10.11591/ijeecs.v10.i3.pp859-866. 150.

[36] Muñoz, M., Gil, J.D., Roca, L., Rodríguez, F., Berenguel, M., "An IoT architecture for water resource management in agro industrial environments: A case study in almería (Spain)", Sensors (Switzerland), 2020 , 20, 596, doi:10.3390/s20030596.

[37] Kim, S., Lee, M., Shin, C., "IoT-Based Strawberry Disease Prediction System for Smart Farming”, Sensors, 2018. doi:10.3390/s18114051

[38] Sabri, N., Mohammed, S.S., Fouad, S., Syed, A.A., AlDhief, F.T., Raheemah, A., "Investigation of Empirical Wave Propagation Models in Precision Agriculture", MATEC Web Conf., 2018, 150, 06020, doi:10.1051/matecconf/201815006020.

[39] Lin, H., Cai, K., Chen, H., Zeng, Z., "The Construction of a Precise Agricultural Information System Based on Internet of Things", Int. J. Online Eng., 2015, 11, 10, doi:10.3991/ijoe.v11i6.4847.

[40] Shashi Rekha, N., Kousar Nikhath, A., Nagini, S., Sagar, Y., Sukheja, D., "Sustainable and Portable Low Cost IOT Based Terrace Model to Grow True Organic Greens", Int. J. Eng. Adv. Technol., 2019, 8, 3223-3228, doi:10.35940/ijeat.F8826.088619.

[41] Divya Vani, P., Raghavendra Rao, K., "Measurement and Monitoring of Soil Moisture using Cloud IoT and Android System", Indian J. Sci. Technol., 2016, 9 , doi:10.17485/ijst/2016/v9i31/95340.

[42] Ruan, F., Gu, R., Huang, T., Xue, S., "A big data placement method using NSGA-III in meteorological cloud platform", Eurasip J. Wirel. Commun. Netw., 2019. doi:10.1186/s13638-019-1456-7.

[43] Potamitis, I., Eliopoulos, P., Rigakis, I., "Automated Remote Insect Surveillance at a Global Scale and the Internet of Things", Robotics 2017, 6, 19, doi:10.3390/robotics6030019

[44] Jayaraman, P., Yavari, A., Georgakopoulos, D., Morshed, A., Zaslavsky, A., "Internet of Things Platform for Smart Farming: Experiences and Lessons Learnt. Sensors", 2016, 16, 1884, doi:10.3390/s16111884.

[45] Watanabe, M., Nakamura, A., Kunii, A., Kusano, K., Futagawa, M., "Fabrication of Scalable Indoor Light Energy Harvester and Study for Agricultural IoT Applications", J. Phys. Conf. Ser., 2015. doi:10.1088/1742-6596/660/1/012110.

[46] Cruz, F.R.G., Ballado, A.H., Alcala, A.K.A., Legaspi, A.K.S., Lozada, E.L., Portugal, V.L.P., "Wireless soil moisture detection with time drift compensation" In Proceedings of the AIP Conference Proceedings, Maharashtra, India, 5-6 July 2018.

[47] Figueroa, M., Pope, C., "Root System Water Consumption Pattern Identification on Time Series Data" ,Sensors, 2017,. doi:10.3390/s17061410.

[48] Lammie, C., Olsen, A., Carrick, T., Rahimi Azghadi, M., "Low-Power and High-Speed Deep FPGA Inference Engines for Weed Classification at the Edge", IEEE Access, 2019. doi:10.1109/ACCESS.2019.2911709

[49] Reynolds, D., Ball, J., Bauer, A., Davey, R., Griffiths, S., Zhou, J., "CropSight: A scalable and open-source 
information management system for distributed plant phenotyping and IoT-based crop management", .Gigascience, $\quad 2019, \quad 8, \quad 1-11$, doi:10.1093/gigascience/giz009.

[50] Syafarinda, Y., Akhadin, F., Fitri, Z.E., Widiawan, B., Rosdiana, E., "The Precision Agriculture Based on Wireless Sensor Network with MQTT Protocol", IOP Conf. Ser. Earth Environ. Sci. 2018. doi:10.1088/17551315/207/1/012059.

[51] Domínguez-Niño, J.M., Oliver-Manera, J., Girona, J., Casadesús, J., "Differential irrigation scheduling by an automated algorithm of water balance tuned by capacitance-type soil moisture sensors", Agric. Water Manag., 2020. doi:10.1016/j.agwat.2019.105880.

[52] Azimi Mahmud, M.S., Buyamin, S., Mokji, M.M., Abidin, M.S.Z., "Internet of Things based Smart Environmental Monitoring for Mushroom Cultivation", Indones. J. Electr. Eng. Comput. Sci., 2018, 10, 847, doi:10.11591/ijeecs.v10.i3.pp847-852

[53] Trilles, S., González-Pérez, A., Huerta, J., “A Comprehensive IoT Node Proposal Using Open Hardware. A Smart Farming Use Case to Monitor Vineyards", $\quad$ Electronics, 2018. doi:10.3390/electronics7120419.

[54] Laktionov, I.S., Vovna, O.V., Bashkov, Y.O., Zori, A.A., Lebediev, V.A., "Improved Computer-oriented Method for Processing of Measurement Information on Greenhouse Microclimate" Int. J. Bioautomation, 2019, 23, 71-86, doi:10.7546/ijba.2019.23.1.71-86

[55] Idbella, M., Iadaresta, M., Gagliarde, G., Mennella, A., Mazzoleni, S., Bonanomi, G., "Agrilogger: A new wireless sensor for monitoring agrometeorological data in areas lacking communication networks", Sensors, (Switzerland) 2020, 20, 1589, doi:10.3390/s20061589.

[56] Erazo-Rodas, M., Sandoval-Moreno, M., MuñozRomero, S., Huerta, M., Rivas-Lalaleo, D., Naranjo, C., Rojo-Álvarez, J., "Multiparametric Monitoring in Equatorian Tomato Greenhouses (I): Wireless Sensor Network Benchmarking”, Sensors, 2018. doi:10.3390/s18082555

[57] Zhang, W., He, Y., Liu, F., Miao, C., Sun, S., Liu, C., Jin, J., "Research on WSN Channel Fading Model and Experimental Analysis in Orchard Environment", In IFIP Advances in Information and Communication Technology, Springer: Berlin/Heidelberg, Germany, 2012.

[58] Muzafarov, F., Eshmuradov, A., "Wireless sensor network based monitoring system for precision agriculture in Uzbekistan", TELKOMNIKA
Telecommun. Comput. Electron. Control, 2019. doi:10.12928/telkomnika.v17i3.11513.

[59] R. Sharama, J. U. Shankar and S. T. Rajan, "Effect of Number of Active Nodes and Inter-node Distance on the Performance of Wireless Sensor Networks," 2014 Fourth International Conference on Communication Systems and Network Technologies, Bhopal, 2014, pp. 69-73, doi: 10.1109/CSNT.2014.22.

[60] Lea, P., "Long-Range Communication Systems and Protocols (WAN)" In Internet of Things for Architects: Learn to Design, Implement and secure your IoT infrastructure, Packt Publishing: Birmingham, UK, 2018.

[61] Fernandez-Ahumada, L.M., Ramirez-Faz, J., TorresRomero, M., Lopez-Luque, R., "Proposal for the Design of Monitoring and Operating Irrigation Networks Based on IoT, Cloud Computing and Free Hardware Technologies", Sensors, 2019. doi:10.3390/s19102318.

[62] Miriam Carlos-Mancilla, Ernesto López-Mellado, Mario Siller, "Wireless Sensor Networks Formation: Approaches and Techniques", Journal of Sensors, 2016. https://doi.org/10.1155/2016/2081902

[63] Boonchieng, E., Chieochan, O., Saokaew, A., "Smart Farm: Applying the Use of NodeMCU, IOT, NETPIE and LINE API for a Lingzhi Mushroom Farm in Thailand", IEICE Trans. Commun. 2018, 16-23, doi:10.1587/transcom.2017ITI0002.

[64] Liu, N., Cao, W., Zhu, Y., Zhang, J., Pang, F., Ni, J., "The Node Deployment of Intelligent Sensor Networks Based on the Spatial Difference of Farmland Soil", Sensors, 2015. doi:10.3390/s151128314.

[65] Zhang, X., Zhang, J., Li, L., Zhang, Y., Yang, G., "Monitoring Citrus Soil Moisture and Nutrients Using an IoT Based System", Sensors, 2017, 17, 447, doi:10.3390/s17030447.

[66] Lee, S., Jeong, Y., Son, S., Lee, B., "A Self-Predictable Crop Yield Platform (SCYP) Based On Crop Diseases Using Deep Learning”, Sustainability, 2019. doi:10.3390/su11133637

[67] Algarín, C.R., Cabarcas, J.C., Llanos, A.P., "Low-Cost Fuzzy Logic Control for Greenhouse Environments with Web Monitoring", Electronics, 2017. doi:10.3390/electronics6040071.

[68] Adenugba, F., Misra, S., Maskeliunas, R., Damasevicius, R., Kazanavicius, E., "Smart irrigation system for environmental sustainability in Africa: An Internet of Everything (IoE) approach”, Math. Biosci. Eng., 2019. doi: $10.3934 / \mathrm{mbe} .2019273$. 